\title{
O VALOR SOCIAL DO TRABALHO E O PRINCÍPIO DA FRATERNIDADE: REFLEXÕES SOBRE 0 TELETRABALHO
}

DenISE Fincato

Advogada. Professora do Programa de Pós-Graduação em Direito da PUCRS. Pesquisadora. Email: denisefincato@gianellimartins.com.br

\section{Resumo}

O artigo estuda o instituto do teletrabalho no contexto principiológico-constitucional. Analisa se a nova modalidade de prestaçáo de trabalho subordinado realiza o valor social do trabalho e, em especial, o princípio (jurídico) da fraternidade. Conclui no sentido de que as redes sociais, ferramentas e espaços onde o teletrabalho se desenvolve, apesar de opiniōes em contrário, podem servir à comunhão humana e à interação laboral, devendo existir um pacto coletivo (público e privado) nesse sentido.

\section{Palavras-chave}

Valor Social do Trabalho; Princípio da fraternidade; Teletrabalho.

\section{Resumen}

El artículo examina el teletrabajo en el contexto principiológico constitucional. Analiza si la nueva forma de proporcionar empleo realiza el valor social del trabajo y en particular el principio (legal) de la hermandad. Concluye en el sentido de que las redes sociales, herramientas y espacios en los que el teletrabajo se desarrolla, además de las opiniones en contrario , pueden servir a la comunión y a la interacción humanas en el trabajo, necesarios para el desarrollo de la fraternidad, debiendo existir un pacto colectivo (público y privado ) para eso fin.

\section{Palabras clave}

Valor Social del Trabajo; Principio de la hermandad; Teletrabajo.

\section{Introdução}

O valor social do trabalho constitui-se em um dos eixos para o sistema normativoconstitucional brasileiro e contribui de maneira decisiva para a significaçáo do "Estado 
Democrático de Direito". As raízes deste dispositivo constitucional encontram-se em documentos históricos e internacionais, uma vez que brotam da evolução espiralada dos direitos humanos, que vão sobrepondo-se em dimensões. O valor social do trabalho, portanto, encontra-se muito bem confortado na $3^{\text {a }}$ dimensão dos direitos fundamentais que alberga os chamados "direitos de fraternidade".

Dentre os diversos fatores que ocasionaram alteraçóes nos regimes de trabalho, destacam-se a realidade econômica, os altos índices de desemprego, o fenômeno da globalização, as transformações tecnológicas e, evidentemente, os desequilíbrios no mercado de trabalho, fatos e circunstâncias comuns aos países iberoamericanos nos últimos anos. Neste contexto, as novas formas de trabalho, como o trabalho a distância, cada vez mais, ganham força.

$\mathrm{O}$ avanço das tecnologias de comunicação e informação contribui para novas concepções de trabalho. Trata-se de uma reestruturação nas relaçóes de trabalho, que leva ao aparente paradoxo sistemático: como promover o valor social do trabalho e concretizar o princípio da fraternidade diante da utilização, cada dia em maior escala, do teletrabalho? O problema surge especialmente a partir do aparente isolamento do teletrabalhador e da pulverização da organização coletiva, prováveis reflexos do trabalho a distância.

Nesta senda, em continuidade à busca da realização do princípio do livre trabalho e da garantia de igualdade de acesso deste às pessoas desiguais (realização dos princípios da liberdade e da igualdade em si), surge a necessidade de pensar a concretização do "princípio esquecido": a fraternidade.

O estudo terá como contexto o cenário brasileiro das atuais relaçôes trabalhistas. Contudo, é necessário observar o que ocorre no mundo, salientando que é crescente o número de "teletrabalhadores", especialmente na Europa e Estados Unidos, em decorrência da difusão da Internet e da flexibilidade das empresas na contratação de determinadas e específicas tarefas. O teletrabalho é modalidade de trabalho emergente de/em tal cenário e exige, inequivocamente, o uso da telemática.

A Constituição brasileira de 1988 estabeleceu, no art. 1º, os princípios fundamentais da República, contemplando a dignidade da pessoa humana e os valores sociais do trabalho. Nesse diapasão, impende lançar luz sobre a problemática que gravita ao redor do teletrabalho a despeito da possível existência de um isolamento social do laborista, seja por discriminação do empregador ou pela insuficiência dos instrumentos tecnológicos de comunicação para capacitar o salutar convívio social do operário, intentando perquirir os limites de atuação dos aludidos mecanismos para edificar alguns alicerces sólidos acerca da temática posta à contenda.

Com meridiana obviedade, o instituto do teletrabalho passa pela simpatia social, vez que dele avultam diversos benefícios. No foco deste estudo, entretanto, advoga-se a ideia 
de que se deve antever as moléstias dele advindas, como forma de impedir ou amenizar seus efeitos.

Assim, em prol do verdadeiro avanço da humanidade (de forma digna e justa), revela-se importante este estudo, que foca na intersecção entre a moderna forma de trabalho (teletrabalho) e o princípio da fraternidade, sempre com o objetivo de efetivar-se o valor social do trabalho.

\section{Do Valor Social do Trabalho}

O valor social do trabalho esteia-se em diversas construçóes de caráter constitucional, especialmente na área de direitos fundamentais. Como pré-apontado, o estudo do valor social do trabalho pressupóe a análise das dimensóes dos direitos fundamentais para, especialmente, observar a $3^{a}$ dimensão: os direitos de solidariedade e fraternidade, difusos em essência.

O valor social do trabalho é positivado em documentos internacionais (Declaração Universal dos Direitos do Homem, por exemplo) e, nacionalmente, repete-se na Constituição Federal de 1988 (art. 170).

Jurisprudencialmente vê-se em decisóes dos Tribunais Regionais do Trabalho menção ao "valor social do trabalho" em alguns acórdãos, notoriamente ao debater o impacto de dispensas discriminatórias ou, ainda, ao forçar o cumprimento de alguns regimes de cotas (pessoas com deficiência, v.g.).

A afirmação do valor social do trabalho é essencial em Estados Democráticos e, normalmente, convive com a livre iniciativa, estando a ela associada em textos constitucionais, como a face oposta de uma mesma moeda.

O trabalho possui uma valoração entre os seres humanos. Esta valoração flutuou muito ao longo da história das relações. Inicialmente tido como natural e para consumo próprio (pré-história), em passos seguintes, viria a traduzir-se em instrumento de dominação (escravidão, servidão, etc.), atrelando-se à ideia de desmerecimento social e, até, de castigo (tripallium).

A evolução da razão humana e, principalmente, de alguns ideais calcados e/ou transformados em princípios basilares para o convívio humano sadio foi transformando o trabalho-dever ${ }^{1}$ em trabalho-direito. Assim, por exemplo, a liberdade de trabalho se

1 Embora existam coerentes argumentaçôes no sentido de que trabalho-dever não é conceito depreciativo ou de cunho negativo. Ao contrário, estaria lastreado no princípio da fraternidade, "manifestando-se como um dever genérico com a sociedade, ou seja, como uma parcela de contribuição que compete a cada cidadão para a melhoria da coletividade" uma espécie de dever metaindividual, portanto, correspondente a direitos genéricos e difusos de bem estar, recíproco e geral (FONSECA, 2009. p. 109). 
consolida e se positiva (fim da escravidão, das corporaçóes de ofício, etc.), e as ideias de trato "desigual aos desiguais", em âmbito laboral, concretizam-se em diretrizes internacionais (convençôes da OIT, por exemplo) e nacionais (a própria Consolidação das Leis do Trabalho é exemplo de ordenamento protetivo ao mais frágil, objetivando igualar juridicamente os que são social e economicamente desiguais), com forte influxo dos fundamentos da Justiça Social.

Digressóes a parte, o valor social atribuído ao trabalho seria bem avaliado, para este estudo, à luz do "princípio da progressão social”, justificador, inclusive, da ramificação principiológica trabalhista, explicitada pelo uruguaio Plá Rodriguez e que tem como carro-chefe o princípio da proteção. Pois o princípio da progressão social, no ordenamento brasileiro, encontra-se já no caput do artigo $7^{\circ}$ da Constituição Federal de 1988, ao dizer-se que os direitos contidos ali ou em outros diplomas "visam a melhoria da condição social" de trabalhadores urbanos e rurais.

Ou seja, não se trata de mero sustento, trata-se de alcançar pelo meio considerado pela sociedade como moral e ético (o trabalho), os mecanismos, relaçóes e objetos que tragam bem estar e felicidade ao trabalhador e sua família. O trabalhador almeja o status de partícipe da sociedade. Anima-lhe a ideia de pertencente ao grupo social, de possuir relevância enquanto ser humano. Isto também faz necessário discutir, então, o viés isolacionista que poderá redundar do uso do teletrabalho. Manter o laborista em sua casa, teletrabalhando, lhe tolheria o direito à inclusão social promovida por meio do convívio no ambiente laboral? O trabalho, neste caso, teria valor social?

O trabalho humano é a força propulsora de uma nação, gera riqueza e desenvolvimento. Entretanto, quando dissociado da preocupaçáo com os aspectos sociais pode gerar quadros drásticos de extrema exploração, de desigualdade na distribuição de riquezas, de segregação dos incapacitados e, portanto, de desvios de seu desiderato mediato, que vai além do sustento do trabalhador e de sua família (fim imediato), proporcionando a inclusão deste e dos seus à vida social, econômica e política de um país. Neste sentido:

[...] o valor da força de trabalho, ou, em termos mais populares, o valor do trabalho, é determinado pelo valor dos artigos de primeira necessidade ou pela quantidade de trabalho necessária à sua produção. [...] Mas há certos traços peculiares que distinguem o valor da força de trabalho dos valores de todas as demais mercadorias. O valor da força de trabalho é formado por dois elementos, um dos quais puramente físico, o outro de caráter histórico e social (MARX, 1978, p. 90-95)

Mede-se o valor atribuído por uma nação aos aspectos sociais derivados do trabalho pela (pré)ocupação dispensada à classe trabalhadora, o que se concretiza nas legislaçóes que regulam a organização do processo produtivo e também pelas políticas sociais (especialmente trabalhistas) implementadas pelo Estado e sua efetiva destinação. 
$\mathrm{Na}$ seara constitucional brasileira, o trabalho é historicamente entendido como um direito fundamental de caráter metaindividual. Veja-se:

- Constituição Federal de 1937, Art. 113. "A todos cabe o direito de prover à própria subsistência e à de sua família, mediante trabalho honesto. O poder público deve amparar, na forma da lei, os que estejam na indigência”;

- Constituição Federal de 1967: “Título III. Da Ordem Econômica e Social. Art. 160: A ordem econômica e social tem por fim realizar o desenvolvimento nacional e a justiça social, com base nos seguintes princípios: ... II. valorização do trabalho como condição da dignidade humana";

- Constituição Federal de 1988: "Da Ordem Econômica e Financeira - Capítulo I - Dos princípios gerais da atividade econômica. Art. 170. A ordem econômica, fundada na valorização do trabalho humano e na livre iniciativa, tem por fim assegurar a todos existência digna, conforme os ditames da justiça social, observados os seguintes princípios: [...] VIII - busca do pleno emprego [...].".

Os significados de "dignidade humana" e de "necessidades normais" do trabalhador, conceitos imbricados, onde a realização da segunda garante a existência da primeira, serão dados pela condição real de vida da classe trabalhadora (no caso, a brasileira), muitas vezes em vazáo tremendamente inferior à pretendida pelo texto constitucional.

A Constituição Federal de 1988 ampliou sensivelmente os Direitos Sociais entendidos como realizadores da dignidade advinda e/ou geradora da ideia de inclusão ${ }^{2}$. Destarte, o valor do trabalho corresponderia ao valor da dignidade humana, dignidade esta circunscrita notoriamente pelos direitos listados (acredita-se que exemplificativamente) no artigo 7o inciso IV da Constituição de 1988: alimentação, habitação, vestuário, higiene, transporte, enfim, direitos que permitem uma boa condição social e, preferencialmente, a melhoram.

Todo o arcabouço legislativo deve observar e contribuir para o cumprimento dos desideratos principiológicos. Na esfera laboral, pelo valor social que se empresta ao trabalho, entende-se como princípio mestre o princípio da progressão social ${ }^{3}$ (LIMA, 1994), este

2 Art. 60. São direitos sociais a educação, a saúde, o trabalho, o lazer, a segurança, a previdência social, a proteção à maternidade e à infância, a assistência aos desamparados [...]; bem como amplia a cobertura do salário mínimo aos trabalhadores;

Art. 7o. [...] IV - salário mínimo, fixado em lei, nacionalmente unificado, capaz de atender a suas necessidades vitais básicas e às de sua família com moradia, alimentação, educação, saúde, lazer, vestuário, higiene, transporte e previdência social, com reajustes periódicos que lhe preservem o poder aquisitivo, sendo vedada sua vinculação para qualquer fim.

3 LIMA, F.M.M. Os princípios do direito do trabalho na lei e na jurisprudência. São Paulo: LTr, 1994. 
a sua vez deflagrador da proteção da relação de emprego e do empregado, já que cediça a compreensão de que a progressão social advirá do trabalho.

A hipervalorização dos resultados econômicos sobre os humanístico-sociais pode levar a sociedade ao caos, fomentando o aumento indiscriminado do rol dos excluídos o que, juntamente com a violência urbana, pode levar até a uma ruptura social. Neste sentido encontra-se Rodrigo Deon (DEON, 2004) que alerta para a necessidade de reconhecimento e efetivação do princípio da valorização do trabalho:

Entretanto, a globalização da economia, por meio de seus instrumentos, como a revolução tecnológica, inferiorizou o homem à condição de mero instrumento de trabalho, substituindo-o pela máquina e priorizando o capital sobre o valor da dignidade humana. É claro que se deve buscar o progresso econômico do país, no entanto o desenvolvimento político, o econômico e o social devem estar harmonizados com o ordenamento jurídico, para que os direitos fundamentais não sejam ignorados na relação de trabalho.

E Renault (2004, p.75) acentua o perigo de se entender o trabalho meramente como um bem material:

Note-se, acima de tudo, que ainda é necessária a erradicação por completo da mentalidade de que o trabalho, qualquer que seja o sistema de produção, é um simples bem material, que só interessa ao indivíduo e não a toda a sociedade; é indispensável o convencimento por parte de alguns setores produtivos de que a organização do trabalho alheio "deslizou" definitiva e irremediavelmente, há mais de um século, do plano puramente contratual para uma necessária e indispensável dimensão de tutela, pouco importando se o sistema da produção é rígido ou flexível, fordista ou toyotista.

O conteúdo axiológico do trabalho não tem sido devidamente observado, uma vez que até a economia o considera como apenas elemento do sistema econômico de um país, reduzindo-o a um aspecto "desumanizado da sociedade". Mera peça de uma engrenagem. Lamentável equívoco que retira do labor seu mais importante significado: a dignidade que confere ao ser humano. Arruda (1998, p.4) enfrenta alguns dos efeitos da globalização, tais como o trabalho transnacional que pode, inclusive, se dar a distância:

A globalizaçáo intensifica a abertura de mercados e a migração de empresas para países e localidades que sejam mais lucrativas, ou seja, onde existe a mão-de-obra mais barata e a menor fiscalização e respeito aos direitos internacionalmente conhecidos como fundamentais para a classe trabalhadora. Além disso, o neoliberalismo privilegia a lógica exclusiva do mercado em detrimento do homem, desviando o avanço tecnológico para o fator lucro, em vez de ter como destinatário a valorização da vida humana. 
Vanguardista é o pensamento que vislumbra o desenvolvimento de um país não pelo grau de riquezas acumuladas, mas pela qualidade de vida de seu povo. E esta premissa, em nível de gestão estatal, notoriamente de definição de prioridades nas políticas públicas, de forma nenhuma pode ser ignorada, sob pena de subverter-se o conceito da finalidade do Estado que consiste na promoção do bem comum. Fica claro, então, que o abandono dos princípios constitucionais referentes à dignidade do trabalhador constitui-se numa tentativa de desmantamento do próprio Direito do Trabalho, uma vez que a atenuação daqueles leva indiscutivelmente ao esfacelamento do aparato jurídico e jurisdicional trabalhista.

A dignidade da pessoa humana encontra suporte no trinômio: liberdade, igualdade e fraternidade. Estes princípios encontram-se em diversos documentos internacionais que afirmam os direitos humanos, indicando-se seu nascedouro na Revolução Francesa (1789). A Constituição brasileira de 1988 também os menciona, positivando-os.

Entretanto, em qualquer esfera jurídica, e especialmente no âmbito laboral, veem-se construçôes legislativas e jurisprudenciais avançadíssimas em direção aos dois primeiros princípios (liberdade e igualdade) e nada ou pouca produção acerca da fraternidade. Guise-se, por oportuno, que se está a analisar a significação jurídica dos mesmos e não seus aspectos sociológico-cristãos (embora sobre o primeiro tenham certa influência). Alguns autores $^{4}$ apontam-no como o "principio esquecido" na evolução jurídica dos direitos humanos.

Entendendo-se a fraternidade como um princípio ativo, motor do comportamento e da ação dos homens, com uma conotação essencialmente moral, revelando os deveres dos homens para com a sociedade (local, nacional, internacional, ou seja, global), é que se avança no estudo. Em que o princípio da fraternidade poderia contribuir para esse estudo?

\section{Do Princípio da Fraternidade nas Relações de Trabalho}

A fraternidade em si, não vista como categoria jurídica, remete a ideias de amor entre irmãos, espontâneo e natural, como sói ser o amor intrafamiliar. Pois a espontaneidade é o elemento que mais dificulta sua compreensão como instituto jurídico, já que o Direito (notoriamente o positivado) é dotado de coercitividade.

Buscando o termo nos textos bíblicos, vê-se que está atrelado à noção de consanguinidade, família, tribo ou de pessoas ligadas por um forte elo comum, tal qual a fé.

4 Neste sentido, ver: ZAMAGNI, S. Fraternità, il principio dimenticato.In: Giornale Agorà. Intervista a Marco Girardo. 3 out.2009, p.25; BAGGIO, A.M. O principio esquecido 1. A fraternidade na reflexáo atual das ciências políticas. São Paulo: Cidade Nova, 2008; BAGGIO, A.M. O principio esquecido 2. Exigências, recursos e definiçóes da fraternidade na política. São Paulo: Cidade Nova, 2009. 
O princípio da fraternidade encontra conexão exata com a $3^{\text {a }}$ dimensão dos direitos fundamentais. Deveria ser naturalmente observado pela coletividade evoluída na consciência e práticas pertinentes aos princípios que também compóem a tríade, mas que se afirmaram com mais brevidade e força (por motivos políticos e econômicos notoriamente): liberdade e igualdade.

No entanto, é cediço que sequer liberdade e igualdade encontram-se perfeitamente acomodadas na cultura jurídica dos povos, especialmente no que toca ao Brasil. Que dizer então da fraternidade?

Neste sentido, muito ajudam as palavras de Panella citado por Baggio (2008, p.13):

[...] diferentemente dos conceitos de liberté e égalité, a importância da fraternidade não é nem jurídica nem institucional, sujeita, mais do que os outros dois, aos abalos da política prática. Daí a necessidade de uma sua reconsideração e, provavelmente, de uma sua reavaliação de natureza não mais politológica, mas sim de base antropológica.

Por isto, acredita-se que o resgate do princípio da fraternidade, como componente inseparável do trinômio e, ao mesmo tempo, como evolução dos mesmos para uma cultura de direitos e responsabilidades com características metaindividuais e solidárias contribuiria para a efetivação do direito fundamental ao trabalho e daí, dado o respeito ao valor social que lhe é intrínseco, geraria transformaçôes sociais importantes. Neste sentido Barros, citada por Baggio (2008, p.13): “[...] somente a "trilogia” no seu todo, com a relação dinâmica entre os três princípios, confere fundamento adequado às políticas dos direitos humanos."

Portanto, as relaçôes sociais e de trabalho devem estar eivadas, em sua construção política, dos princípios consagrados no cenário da revolução. É da inter-relação entre eles que advém a eficácia das estratégias de direitos humanos.

Pelo esquecimento do princípio da fraternidade, como um princípio-guia das açóes humanas, segue certa resistência às ideias (e ideais) de inclusão ou, pior, realizam-se inclusóes "plásticas", com o objetivo único de cumprir a legislação de cotas, v.g., desparceiradamente do compromisso social que a mesma traz em si. Assim, nos dizeres de Rawls (2008, p.16):

[...] no confronto com as ideias de liberdade e de igualdade, a ideia de fraternidade sempre teve um papel secundário na teoria da democracia. Ela é pensada como um conceito especificamente menos político do que os outros, por não definir, de per si, nenhum dos direitos democráticos (como a igualdade ou a liberdade em si mesmas), mas incluir muito mais certas atitudes mentais e certas linhas de conduta, sem as quais se perderiam de vista os valores expressos por estes direitos. 
Nesta pesquisa, entretanto, o termo fraternidade será tomado como

[...] uma categoria relacional da humanidade, superando inclusive o conceito aristotélico de amizade política onde por meio dele o filósofo grego defendia que os cidadãos se unem, em consenso, para instituir uma determinada comunidade política. [...] A idéia de fraternidade que se pretende difundir exprime igualdade de dignidade entre todos os homens, independentemente de organização em comunidades politicamente institucionalizadas (MACHADO, 2011).

Por oportuno, registre-se que há certa compreensão de que a fraternidade seria mais um instituto auxiliar ao Direito ou até mesmo algo metajurídico. Por isto, será necessário o esforço em demonstrar sua natureza jurídica, especialmente à luz do constitucionalismo, onde o direito do trabalho de diversos países finca raízes importantes.

Pois bem, é na seara da fundamentalidade que se trabalha. Para além e muito antes do Direito positivado há um conjunto de prerrogativas que o ser humano possui e que devem ser respeitadas pelo simples fato de serem inerentes a todo o ser humano. Tais prerrogativas, tais direitos, são indisponíveis e, por isto, inalienáveis, imprescritíveis e irrenunciáveis. Sua consagração foi crescente e conexa à evolução da organização social dos seres humanos e guarda estreita relação com a necessidade de contenção do poder do governante absoluto e do próprio Estado frente ao cidadão (ao ser humano).

Podem-se apontar raízes ainda mais antigas, calcadas em ideários e desideratos humanistas e que marcaram o constitucionalismo moderno, tais como a Declaração da Virgínia (1776) e a Declaração dos Direitos do Homem e do Cidadão (1789), onde se deu especial ênfase ao trinômio liberdade, igualdade e fraternidade, ao lado de outro, à época também tido como valor importante aos revolucionários: a propriedade.

Seguiu-se movimento de internalização dos direitos humanos, com consequente constitucionalização em diversos países. Naquele momento, a principal preocupação dos países era constitucionalizar a chamada $1^{\text {a }}$ Dimensão (ou Geração) de direitos fundamentais, fortemente calcada no valor liberdade, principalmente na garantia das liberdades do indivíduo frente ao seu Estado.

A evolução do pensamento liberal para outras bases, levou à transição do Estado Liberal para o Estado Social. Então, vieram à tona os chamados direitos de 2a Dimensão (ou Geração), com especial destaque para o valor igualdade. É a vez dos direitos sociais serem inseridos nas cartas constitucionais e despontam como pioneiros o México (1917) e a Alemanha (1919), seguidos por muitos outros países, como o Brasil (1934). Importante para a área trabalhista, por isto merecendo referência, a Declaração dos Direitos do Povo Trabalhador e Explorado (Rússia, 1918). O conjunto da constitucionalização dos direitos sociais e das declaraçóes com o conteúdo supra, levaram ao Tratado de Versailles (1919) que criou a Organização Internacional do Trabalho. Os direitos de 2a Dimensão 
são direitos de prestação estatal, exigíveis pelo cidadão de forma individual ou por grupos individualizáveis e que se materializariam, precipuamente, em políticas públicas.

No entanto, o constante amadurecimento da teoria dos direitos fundamentais (é bem verdade, por vezes impulsionado por eventos catastróficos, como a 2a Grande Guerra) levou à percepção de que as duas primeiras dimensóes eram limitadas e que, algumas garantias pertenciam à humanidade em seu todo, presente ou futura, sendo devidas também por toda a humanidade, presente ou futura.

Caminhava-se no sentido da consagração dos direitos de fraternidade (o terceiro integrante do trinômio inicial) ou de solidariedade e, consequentemente, para um novo modelo de Estado: o fraternal (SARLET, 2004, p.56), o que levaria à consolidação dos Direitos de $3^{\text {a }}$ dimensão.

Neste sentido, em 1945, surge a Carta da Organização das Naçóes Unidas, que a institui como pessoa jurídica de direito internacional, com vida independente dos países que a constituem, formam e mantém e que, já em seu preâmbulo reforça os três valores-lema da Revoluçáo Francesa de 1789, com especial enfoque para o solidarismo e a fraternidade.

No fluxo deste movimento universalizador dos direitos fundamentais, em 1948, a Assembleia Geral da ONU aprova a Declaração Universal dos Direitos Humanos que toma por base a declaração de 1789, mas a aperfeiçoa, notoriamente ao impor a todos o dever pelo respeito aos direitos humanos, que são de todos. Paulatinamente, as constituiçôes dos países vão inserindo dispositivos de transcendência aos seus tradicionais limites soberanos. E nem se está falando dos países europeus, integrantes da União Europeia. $\mathrm{O}$ Brasil, com a emenda constitucional no 45 de 2004 , acrescentou o $\$ 3^{\circ}$ ao artigo $5^{\circ}$, pelo que se comprometeu a considerar como se emenda constitucional fossem os tratados internacionais com conteúdo de direitos humanos aprovados no sistema de ratificação brasileiro, com votação em dois turnos e por 3/5 dos votos dos membros do Congresso Nacional.

Enfim, resta latente que o Direito existe em razão do homem e de suas relaçôes com os demais. Nestes relacionamentos, parte-se da premissa de que todos os seres humanos são livres, iguais e dotados de dignidade. Todos estes valores são intrínsecos à sua mera existência humana, sem condicionantes de qualquer categoria ou tipo. É então que Machado (2011) complementa

Partindo desse novo paradigma, o caráter relacional e intersubjetivo dos direitos - relação entre sujeitos - receberá novos contornos. Não se concebe uma intersubjetividade excludente. Precisamos compreender o Direito como um instrumento que regulamenta condutas visando fazer com que os seres humanos vivem [sic] com o outro e não apesar do outro.

Em cada ser humano habita, num certo sentido, toda a humanidade. $\mathrm{O}$ outro, também sou eu. Tudo se reduz à unidade. Tudo é "um”. 
Empiricamente até, é possível atestar o êxito de diversos Estados em garantir, nos limites do seu possível, a liberdade e a igualdade. No entanto, mesmo sucesso não se vê com relação à fraternidade, em que pese esteja expressa (escrita, impressa) nos principais documentos de todos os países que se dizem democráticos.

Aí reside o nó górdio: não se concebe, num cenário inter-relacional, liberdade e igualdade sem fraternidade, já que esta é premissa e ao mesmo tempo condição para a concretização daqueles. Mesmo que ainda estivesse no bojo de um Estado Liberal, o rudimento desta compreensão já se via esboçado na Declaração de 1789 , que em seu artigo $4^{\circ}$ rezava: “[...] a liberdade consiste em poder fazer tudo aquilo que não prejudique outrem; assim, o exercício dos direitos naturais de cada homem não tem por limites senão os que asseguram aos outros membros da sociedade o gozo dos mesmos direitos."

Focar apenas na liberdade e na igualdade, olvidando a fraternidade, reforçaria apenas os direitos individuais, estaticamente depositados em um ser humano, desconsiderando que é da relação deste com os demais que se pode, até mesmo, falar em direitos.

A Constituição do Brasil de 1988, ao elencar os objetivos republicanos em seu artigo $1^{\circ}$ expressa em catálise jurídica, disseminadora dos axiomas ali contidos, ser sua missão "construir uma sociedade livre, justa e solidária", donde se vê, claramente, a menção ao trinômio já destacado.

Solidariedade e Fraternidade 5 são conceitos muito próximos no senso comum, podendo-se dizer que a solidariedade, inclusive, amplia a compreensão de fraternidade. Machado (2011), citando o Ministro Carlos Brito, do Supremo Tribunal Federal brasileiro, aponta para a nova fase a ser vivida: o constitucionalismo fraternal ou altruístico. Registra que o Ministro o aponta como o clímax do constitucionalismo, e que reforça sua argumentação com os seguintes termos: "Depois que ele [o constitucionalismo] assumiu uma feição liberal ou libertária, uma função social ou igualitária, agora chega à terceira fase, que é a fraternidade, para ombrear todas as pessoas em termos de respeito, referência e consideração."

Enfim, vislumbra-se uma categoria constitucional: a fraternidade, tal qual a liberdade e a igualdade. E, sem dúvida, esta interfere (porque constitucional) em todo o ordenamento jurídico brasileiro, agindo em todos os tipos e graus de relacionamento humano, inclusive os puramente particulares, como os empregatícios.

Este estudo, ainda, possui o escopo de demonstrar que diversos movimentos e fenômenos não jurídicos, mas com impactos importantes nessa seara, a partir da quebra do

5 FRATERNIDADE: s.f. 1 laço de parentesco entre irmãos. 2 união, afeto entre irmãos. 3 amor ao próximo (p. 360). SOLIDARIEDADE: s.f. 1 cooperação mútua entre duas ou mais pessoas. 2 fig. Interdependência entre seres e coisas. 3 identidade de sentimentos, de idéias, de doutrinas. (p.697) In: HOUAISS, A. e VILLAR, M.de S. Minidicionário da Língua Portuguesa. 3 ed. Rio de Janeiro: Objetiva, 2009. 
paradigma clássico e da instauração de novas bases epistemológicas das relaçóes trabalhistas, geraram novas formas de organização do trabalho. Nessa evolução, cresce também a consciência e positivação da mesma de que todos têm direito ao trabalho, entendendo-se este como um direito fundamental.

É então que, mercê de suas características conceituais e estruturais, reconhece-se como nova forma de trabalho, especialmente a partir da década de 70 do século XX, o teletrabalho, que ainda se encontra em processo de formação e evolução, não existindo acerca do mesmo um consenso conceitual por parte dos estudiosos do assunto, na medida em que tal instituto surge num cenário influenciado por fenômenos econômicos e sociais marcantes, como a globalização e a flexibilização de direitos sociais, embasadores da necessidade de repactuaçóes laborais. Nessa perspectiva, percebe-se que o teletrabalho pode representar uma alternativa à inserção no mercado de trabalho.

\section{Aspectos Gerais do Teletrabalho}

\subsection{Conceituação e Definição}

As conceituaçóes sobre teletrabalho são variadas e se encontram em processo de harmonização. No teletrabalho subordinado, os empregados executarão tarefas fora do ambiente regular da fábrica, utilizando os modernos recursos da informática como mediadores desse relacionamento ímpar (FRANCO FILHO, 1998).

Jack Nilles (1997, p.15), apontado como precursor do teletrabalho, explica que "o teletrabalho [...] visa reduzir ou eliminar as viagens diárias ao trabalho por parte dos funcionários (ou proprietários) de uma empresa”. O trabalho à distância, de acordo com os ensinamentos de Pinho Pedreira (2000, p. 583):

[...] é gênero que compreende várias espécies, uma delas o teletrabalho. Outras modalidades de trabalho à distância podem ser mencionadas, como o trabalho em domicílio tradicional e aquele desenvolvido fora do centro de produção mediante o uso de instrumentos também tradicionais como o telefone, o bip, o rádio etc.".

Teletrabalho pode ser definido, conforme Pollyanna Andrade (2007, p. 285-6), como o labor exercido em um local distinto do centro de trabalho convencional, seja em domicílio ou em local intermediário, no qual o trabalhador não mantém contato pessoal com o empregador, mas pode se comunicar com ele, através dos meios de tecnologia de informação e de telecomunicação, visando a competitividade e flexibilidade nos negócios.

João Hilário Valentim (2000, p.100) propóe que teletrabalho seja conceituado como "a prestação de serviço destinada a outrem e sob a subordinação deste, exercida por um trabalhador, preferencialmente em sua casa e com o suporte se modernos instrumentos e tecnologias relacionados às telecomunicações e informática”, e afirma que o teletrabalho 
não é trabalho a domicílio, embora comumente seja desenvolvido na casa do empregado, não é um trabalho precário ou "informal”, pois devem ser garantidos aos teletrabalhadores os direitos dos trabalhadores comuns, não é trabalho executado todo tempo em casa, porque o trabalhador também pode realizar parte de sua jornada de trabalho na sede da empresa, e, finalmente, não é trabalho típico de informática, eis que o empregado pode executar as tarefas que desenvolvia no escritório, podendo se dar com o suporte do computador, mas também do telefone, do fax, não necessitando essencialmente que o teletrabalhador seja profundo conhecedor de informática (VALENTIN, 2000, p. 98).

Carla Carrara da Silva Jardim (2003, p. 39-40) ressalta que "o teletrabalho consiste, sobretudo, em produção, tratamento, distribuição, exploração e manutenção dos sistemas de informação", acrescenta, ainda, que nos países industrializados o teletrabalho é associado, principalmente, às tarefas administrativas, mas também

[...] é aplicado nas atividades de ensino e de formação, nas companhias de seguros, nos bancos, graças à padronização dos documentos, na venda por correspondência e no telemarketing, nos setores de informática e de telecomunicaçóes, nos serviços de tradução, no tratamento de textos e dados, na imprensa, nas editoras, nas consultorias, entre outras atividades em que também se faz presente o teletrabalho.

Em defesa do teletralho, Jack Nilles (1997, p.27) narra que:

O lar pode ser uma base eficiente para o teletrabalho, permitindo reduçôes de custo significativas para o patrão e para o funcionário, possibilitando às pessoas acesso a empregos que de outro modo poderiam não estar disponíveis, proporcionando ganhos significativos de produtividade e inúmeros benefícios indiretos à sociedade (conservação de energia, redução da poluição etc.). $\mathrm{O}$ aspecto relacionado à redução da poluição atmosférica é um incentivo importante para que muitas organizaçóes adotem o teletrabalho, geralmente em resposta a legislações ambientais cada vez mais rigorosas. Para muitos funcionários, o teletrabalho doméstico funciona somente como uma opção em meio-período.

Pode-se dizer, portanto, que o teletrabalho surge como uma nova modalidade de prestação de serviços, sem cobertura legal específica e satisfatória na maioria dos países até o momento e, ainda, que sua definição não responde a critérios jurídicos, mas, sim, a considerações práticas.

\subsection{Caracterização da Relação de Emprego no Teletrabalho}

A dificuldade na conceituação do teletrabalho é um reflexo da falta de legislação/ regulamentaçáo satisfatória sobre o tema, no entanto, utiliza-se do princípio do contrato-realidade e de alguns dispositivos legais que analogicamente se amoldam a este tipo 
de organização de trabalho, no intuito de que se possa caracterizar ou não a relação de emprego.

Portanto, a prestação de serviços na modalidade teletrabalho cria necessariamente um contrato no qual, se presentes os requisitos dos artigos $2^{\circ}$ e $3^{\circ}$ da CLT, ter-se-á uma relação de emprego, sujeita, portanto, às regras da legislação trabalhista. Entretanto, se o contrato firmado entre as partes não contiver os requisitos caracterizadores da relaçáo de emprego, provavelmente estar-se-á diante de uma relação de teletrabalho autônoma.

Pode-se afirmar que a subordinação é o mais importante elemento para demonstrar o vínculo empregatício. Não sem razão, portanto, o legislador nacional alterou a redação do art. $6^{\circ}$ da CLT para admitir, no Brasil, o exercício da subordinação de forma telemática. Muito se pensou que, com o advento do teletrabalho a subordinaçáo ficaria mitigada, todavia, o emprego da tecnologia não extinguiu o elemento subordinação da relação de emprego, podendo-se afirmar que, ao contrário, intensificou a submissão do empregado às ordens e à supervisão do empregador (OLIVEIRA, 2008, p. 23-9), obrigando, dessa forma, uma reformulação na compreensão do requisito subordinação.

Aplicando-se o princípio da primazia da realidade, configurada a relação de emprego através da observaçáo dos elementos propostos pela legislação celetista, são devidos ao empregado por parte do empregador todos os direitos e deveres inerentes a esta relação contratual, constantes no artigo $7^{\circ}$ da Constituição Federal de 1988, na Consolidação das Leis do Trabalho e outras leis e documentos pertinentes.

\subsection{Considerações Acerca da Natureza Jurídica no Teletrabalho}

$\mathrm{Na}$ análise do teletrabalho, Silva (2000, p.584) entende que a averiguação da natureza jurídica do teletrabalho náo permite uma única resposta, pois depende da forma como se realiza a prestação de serviços, que pode ostentar a fisionomia de autônoma ou de subordinada, em relação a todas as modalidades de teletrabalho.

Em qualquer das suas modalidades, o teletrabalho pode ser prestado de forma autônoma ou subordinada (SILVA, 2002, p. 585). A natureza jurídica da relação, conforme Sérgio Pinto Martins (2001, p. 354):

[...] vai depender do tipo de situação fática que envolva as partes. Pode ser um contrato de trabalho, um contrato de prestação de serviços sem vínculo de emprego etc. [...] Até o presente momento não tem regulamentação, sendo utilizadas normas previstas para outros contratos, que são adaptadas. Poderá ser um contrato de natureza civil, comercial, trabalhista, ou a mistura dos dois primeiros ${ }^{6}$.

6 MARTINS, Sérgio Pinto. Teletrabalho. Repertório IOB de Jurisprudência: Trabalhista e Previdenciário. São Paulo. v. 2, n. 18, 2001. p. 354. 
Dada sua especificidade, o teletrabalho é uma atividade de natureza controvertida, pois apesar de ser um tema em ascensão, principalmente porque requer a flexibilização das normas trabalhistas, para si no Brasil ainda não há regulamentação própria suficiente, o que provoca a carência de proteção jurídica das partes, fazendo com que os julgadores utilizem a analogia para aplicar aos casos em que se verifique o teletrabalho (ANDRADE, 2007, p. 284).

\subsection{Ausência de Regulamentação Pormenorizada do Teletrabalho e sua Compa- tibilidade com as Normas Vigentes}

A falta de uma legislação específica para o teletrabalho faz com que frequentemente se utilize a analogia, o direito comparado ou ampliem-se os efeitos das leis vigentes para enquadrar essa nova forma de trabalho - muito embora atualmente tenha-se a Lei n. ${ }^{\circ}$ 12.551, de 15/12/2011, que alterou o caput do art.6º e acrescentou parágrafo único à aludida norma, limitando-se a admitir o trabalho a distância como forma subordinada de trabalho ${ }^{7}$.

Desta feita, cumpre recordar que a atual Constituição Federal de 1988 prevê, no artigo 7º, inciso XXVII, a proteção do trabalhador em face da automação, na forma da lei. O preceito ainda não foi objeto da indispensável regulamentação legislativa, no entanto, quando vier a ser, certamente abrirá espaço para as questóes relativas ao teletrabalho, eis que dentro da automação, sem dúvida, esse novo mecanismo se inclui (FRANCO FILHO, 1998).

A automação é resultado da adoção das novas tecnologias nos meios de produção, na medida em que, mais que a Revolução Industrial, que mudou completamente o comportamento e as relaçóes de trabalho a partir do século XVIII, as alteraçóes e os avanços tecnológicos dos últimos anos promoveram, de modo excessivamente rápido, modificaçóes demasiadamente profundas nos meios de produção, como por exemplo, a inserçáo do teletrabalho na sociedade laboral, razão pela qual se deve reconhecer a importância e a necessidade da regulamentação minuciosa do tema (FRANCO FILHO, 1998, p. 92).

\subsection{Vantagens e Desvantagens do Teletrabalho}

As inovações tecnológicas trouxeram modificações substanciais nas estruturas sociais, que se estenderam ao funcionamento das organizaçóes, particularmente, no modo de organizar e administrar o trabalho. O teletrabalho é resultado da evolução tecnológica,

7 Como habilmente o fez Portugal, ao inserir diversos e minuciosos artigos no Título "Teletrabalho" de seu Código do Trabalho. 
especialmente das tecnologias de comunicação e informação, sendo possível, de acordo com o prisma por que se observe, verificar vantagens e desvantagens em seu uso.

No que tange as vantagens, entre as primeiras observadas, alinham-se algumas de interesse direto da empresa e do empregado, como diminuição de despesas de transporte, vestuário, combustível e demais custos em geral, aumento da produtividade, racionalização de instalaçóes, equipamentos e material de trabalho. Por sua vez, entre as seguintes observadas, abordam-se algumas de interesse psicossocial do empregado, como liberação das tensões do tráfego na ida e volta do trabalho, supressão da rigidez de horário e liberdade para atendimento, no período de trabalho, de interesses pessoais e familiares incidentais (PINTO, 2000).

A doutrina majoritária aponta como fator importante, a possibilidade do teletrabalho se estender a um contingente humano que enfrenta dificuldade em obter emprego formal, atuando como um meio hábil de contribuição para a diminuição da desigualdade de oportunidades (MORAES, 2009).

Todavia, as vantagens elencadas podem revestir-se de desvantagens para alguns trabalhadores, eis que, por exemplo, o teletrabalho pode significar diminuição do tempo livre, isolamento social, redução da distinção vida profissional/vida particular, menores possibilidades de ascensão profissional, dificuldades para a fiscalização do bom ambiente de trabalho, dentre outras. Outro ponto negativo do teletrabalho é a quebra de privacidade, face às características mesmas dos sistemas internacionais de computação. Há que se cuidar desse aspecto porque existe risco de atentar contra as liberdades individuais e o direito de privacidade, garantido a todas as pessoas (FRANCO FILHO, 1998).

Observa-se, portanto, que o teletrabalho impóe uma mudança não só no aspecto econômico, jurídico e social, mas também no cultural, na medida em que, o fenômeno da globalização, que aproxima os povos e elimina as barreiras, abrange, também, o teletrabalho e é através dele que se deve buscar os instrumentos necessários para, adaptando as empresas e os trabalhadores a essa nova e irreversível realidade, reduzir os níveis de desemprego.

O teletrabalho distingue-se do trabalho tradicional pelo deslocamento da atividade profissional da sede física da empresa para outro local, mais favorável ao empregado. $\mathrm{Ou}$ seja, é realizado em domicílio, telecentros, centros satélites, telecottages, ou sem um espaço definido, quando se falará no teletrabalho nômade ou móvel.

Dentre as modalidades citadas, destaca-se para fins deste estudo o teletrabalho no domicilio do empregado que se tornou possível face à eficiência das novas tecnologias. Seja por intermédio de computadores, telefones, faxes ou outros, o teletrabalhador pode se manter telematicamente conectado com o empregador para a realização da atividade laboral, se esta for a modalidade contratual. 
Desse novo local de trabalho (sua residência) o empregado pode até ser monitorado/ controlado pela empresa com a qual mantém contrato de trabalho. Este monitoramento pode ser feito virtual ou presencialmente, através das novas tecnologias já desenvolvidas para este tipo de trabalho (sistema de logins, biometria, etc.).

Em assim sendo, o teletrabalho (trabalho a distância, mediado por tecnologia de comunicação e informação), que pode ser realizado na própria residência do trabalhador, é visto como alternativa de desconstrução daquele labor executado no ambiente de trabalho - ou seja, o teletrabalho desponta como mecanismo de descentralização do espaço laboral. Nesse passo, indaga-se se a garantia do sustento seria a realização do valor social do trabalho?

\section{Fraternidade e Teletrabalho: Possibilidades}

No sentido do supra estudado, necessário que o Estado novamente se ocupe da tarefa de realizar o princípio que parte do livre trabalho e da "igualização" dos desiguais, mas que chega à fraternidade como seu mote central. Esta ocupação se daria em níveis legislativos (regulamentação do teletrabalho, p.ex.), fiscalizatórios e, permeando os momentos retro, com um intenso movimento formativo-cidadão.

O fio condutor desta atuação, que transcenderia a figura do Estado, atingindo também sindicatos, ONG's, empresas, empregados e cidadãos em geral seria, obviamente, o princípio da fraternidade e o dever de efetivação da $3^{a}$ dimensão dos direitos fundamentais.

Cediço que, nas sociedades pós-modernas, a seara tecnológica vem ganhando relevo e permeando as relaçóes pessoais. À luz dessa razão, exsurgem as redes sociais como instrumentos aptos à efetivação dos aludidos relacionamentos de cunho individual e coletivo, rompendo com os paradigmas de tempo e espaço na promoção dos tratos pessoais.

Castells (1999) aponta que alguns críticos consideram que com a expansão da internet ocorre um isolamento social e uma ruptura da comunicação social e familiar posto que os indivíduos escondem-se no anonimato e praticam relaçóes sociais em espaços não presenciais. Entretanto, o autor considera o debate bastante ultrapassado, uma vez que ele é anterior à expansão generalizada da internet e que teria sido gerado com base em experiências isoladas, além de não existirem pesquisas aprofundadas para comprovar a teoria.

Para o autor a internet possui um importante papel na reestruturação das relaçóes sociais. Um dos fatores mais importantes deste processo é o individualismo como base do novo modelo de sociabilidade. Não se afirma que a web cria um modelo de individualismo em rede, mas que o individualismo em rede, já existente, tem na internet um importante suporte material para que ele se torne forma dominante de sociabilidade. 
O individualismo em rede é um modelo social, ou seja, náo constitui uma rede de indivíduos isolados. As redes existem, on-line e off-line, formadas de acordo com os interesses, valores e afinidades de cada um. Porém, não só por estar em rede formando comunidades, um sujeito perde sua individualidade. Assim, o sujeito pode manter tal sentimento, mas, ao mesmo tempo, fazer parte de relaçóes sociais.

O sujeito fragmentado e múltiplo é aquele conduzido à sociedade em rede. As novas organizaçôes sociais e as novas tecnologias vão alavancar esse sujeito em direção a referências híbridas, gostos cruzados e novas escolhas. Para Castells (1999) "Rede é um conjunto de nós interconectados. Nó é o ponto no qual uma curva se entrecorta. Concretamente, o que um nó é depende do tipo de redes concretas de que falamos”.

O mesmo autor menciona as mudanças sociais que vêm ocorrendo desde o final do século XX e que têm como principal força impulsionadora os movimentos de globalização e avanços tecnológicos, que levam a novas interpretaçóes quanto à sociedade. Para ele a reestruturação do capitalismo e a revolução da tecnologia introduziram a sociedade em rede como nova organização social, com três pontos principais a saber: (a) globalização das atividades econômicas no que diz respeito ao ponto de vista estratégico. Essas se modificam e passam a ser organizadas em rede, tendo como características a flexibilidade e instabilidade do emprego e a individualização da mão-de-obra. O segundo (b) é uma cultura baseada em um sistema de troca de informaçóes onipresente, interligado e diversificado em que é construída uma virtualidade real. E o terceiro (c) é a transformação das bases materiais da vida - tempo e espaço - perante um espaço de fluxos em que o tempo torna-se intemporal.

Para Castells (1999), na sociedade da informação, as informaçóes e os processos dominantes estão organizados em redes, tornando-se, as redes, uma nova morfologia social. Essa lógica reorganizou operaçôes de experiência, de poder e de cultura, de forma que o contexto da sociedade em rede contribuiu com um processo de dissociação entre sociabilidade e localidade e na formação das comunidades, assim, as relaçóes sociais passam a ser regradas por novos modelos, diferentes daqueles determinados pelo território. Neste sentido, o Estado-Nação contemporâneo tem sua soberania relativizada e dá lugar às redes globais de riqueza, de poder e de informação, perdendo assim sua capacidade de intervir em transaçóes globais com base em seu poder político estabelecido pelo território. Ocorre uma dissolução das identidades compartilhadas que representa a dissolução da própria sociedade como sistema social relevante. A construção de identidade legitimadora perde forças de maneira que as instituiçôes e organizaçóes da sociedade civil tornam-se cada vez mais vazias. Esses movimentos propulsionam os processos de fragmentação do sujeito, cuja identidade - em permanente estado de construção, com base em um atributo cultural, ou um conjunto de atributos culturais inter-relacionados - assume múltiplas representaçôes sociais, uma vez que sua constituição se dá em função de tendências sociais 
e projetos culturais enraizados em sua estrutura social, bem como sua visão de tempo/ espaço. Trata-se, portanto de um processo que náo é único e nem finito e que permite ao sujeito pós-moderno uma combinação de valores tradicionais e contemporâneos envoltos por uma esfera de fraternidade.

Nesse contexto, a rede surge como suporte de uma nova ideia de fraternidade mundial e se encontra, aliás, no centro de vários debates, obras, proposiçóes políticas e culturais. Por que não encontrar na rede mundial uma oportunidade para uma nova solidariedade, uma nova consciência fraterna? E o teletrabalho não poderia revelar por sua própria essência uma significação fraterna?

O trabalho proporciona a qualquer trabalhador não só o sustento, mas também a sua aceitação social. O teletrabalho, por seu turno, tem o condão de angariar diversos benefícios ao empregado, ao empregador e à sociedade, vez que alcança o desígnio da mitigação do desemprego, precipuamente no que tange a uma ampliação da dimensão laboral face ao mercado exterior - ou seja, há a possibilidade do empregado se candidatar a inúmeras ofertas de trabalho, inclusive, em nível internacional (HERNANDEZ, 2011, p. 43).

Diante das inúmeras vantagens citadas como inerentes ao teletrabalho, é necessário questionar, também, acerca de um possível isolamento do laborista em virtude do teletrabalho. O teletrabalho, como outrora já se afirmou (FINCATO, 2008) pode ser desvirtuado e utilizado para fins meramente segregatórios, por exemplo, quanto a empregados homossexuais, portadores de HIV, pessoas com deficiência e outros podem ser "escolhidos" para exercer o teletrabalho, o que claramente distorce sua função social. É de trânsito corrente, pois, uma possível mácula sobrevinda da vanguardista relação laboral em mutação, já que esta poderá culminar em um fator de isolamento do laborista - muito embora o sociólogo italiano Domenico de Masi (2000, p. 265) seja preciso em asseverar que o teletrabalho está desvinculado do isolacionismo - o que podemos depreender da passagem abaixo:

O número menor de relacionamentos pessoais aqui do que no escritório, com os colegas, é amplamente compensado pelo maior número de relacionamentos pessoais em família, no edifício, no quarteirão. De resto, em cem cidadãos, apenas uns 30 trabalham em empresas; a socialização, portanto, é mais provável e mais "fisiológica” fora da empresa, no mundo das relaçôes não coagidas.

Sob essa vertente, os itens concebidos anteriormente, não obstante tratarem apenas de aspectos conceituais e legislativos, pugnam com clareza que, independentemente da nomenclatura que cunhe a determinado grupo social, os direitos fundamentais devem ocupar papel basilar no ordenamento jurídico pátrio, se configurando como parâmetro dentro do qual devem ser interpretadas todas as normas trabalhistas. 
Desta feita, a atual Constituição Federal prevê garantias, a exemplo de documentos internacionais e mesmo de legislação anterior à sua promulgação, no sentido de que os direitos fundamentais e a dignidade da pessoa humana devem preponderar sobre os demais enunciados normativos.

O princípio da dignidade da pessoa humana traz consigo a inquestionável essencialidade do labor na vida do ser humano, não só por se tratar da forma como o homem obtém o necessário à sua subsistência, mas por ser instrumento de realização pessoal do indivíduo, tornando-o respeitável perante a sociedade e, principalmente, o incluindo no seio desta, como cidadão, possuidor de direitos e obrigaçóes.

Destarte, considerando que o valor essencial da dignidade da pessoa humana rege todas as manifestaçóes do ordenamento jurídico brasileiro, é possível citar como decorrências desse princípio, o direito à igualdade e proibição de discriminação entre trabalhadores.

No presente estudo deve ser observado, ainda, o princípio do valor social do trabalho, consagrado no art. $1^{\circ}$ da Constituição Federal e abordado por Rafael da Silva Marques (2007, p. 146):

O valor social do trabalho é, e disso não se tem mais dúvidas, ao lado da dignidade da pessoa humana, o elemento principal de toda a Constituição, norma esta pertencente a um Estado Democrático de Direito. Este mesmo Estado, desta forma, apenas existe porque há trabalho humano. Se alguém pode adquirir um bem e dizer "é meu”, é porque há trabalho humano. Trabalho humano, portanto, elemento-chave do Estado, deve ser, de uma vez por todas, tratado como tal. É o que se pretende destacar e chamar a atenção com este estudo.

O autor ainda destaca que o trabalho, por si, não é um conceito econômico, sendo ele um elemento de existência humana. As pessoas trabalham para, muito além de prover sua subsistência, suprir suas demandas, não apenas materiais, mas também existenciais e de vida $\left(2007\right.$, p. 149) ${ }^{8}$.

8 E prossegue o autor (Ibidem): "O trabalho não é apenas um elemento de produção. É bem mais do que isso. É algo que valoriza o ser humano e lhe traz dignidade, além, é claro, do sustento. É por isso que deve ser visto, antes de tudo, como um elemento ligado de forma umbilical à dignidade da pessoa humana. Valorizar o trabalho significa valorizar a pessoa humana, e o exercício de uma profissão pode e deve conduzir ao alcance de uma vocaçáo do homem. Mesmo o mercado, para quem o trabalho nada mais é, isso em uma concepção liberal, do que elemento de produção, não pode prescindir de valorizar o trabalho como elemento crucial ao alcance da dignidade humana [...] é essa, portanto, a função não só dos intérpretes, mas da sociedade. Proteger o trabalho como elemento-cerne da Constituição de 1988, ao lado da dignidade da pessoa humana, realçando qualquer tentativa de violação deste fundamento, quer de forma legislativa, que no mundo dos fatos. A nova hermenêutica constitucional agasalha esta tese, basta boa vontade por parte da coletividade e dos intérpretes" 


\section{Conclusões}

Nessa esteira de raciocínio, pode-se afirmar que o sistema constitucional de proteção ao trabalhador começa pelo princípio da igualdade, que veda qualquer forma de discriminação exercida pelo empregador de maneira direta ou velada, utilizando-se da modalidade de teletrabalho como instrumento de uma "política" isolacionista, conforme se depreende da leitura do caput do artigo $5^{\circ}$ da Carta Magna de 1988, ou seja, à frente de todos os direitos e garantias fundamentais, orientando a interpretação a ser dada aos direitos e deveres individuais e coletivos. Portanto, o princípio da igualdade, também chamado de princípio da isonomia, possui ampla relevância no ordenamento constitucional brasleiro e/ou comparado, posto que assume a função de afastar todo tipo de discriminação e tratamento desigual aos cidadãos.

O princípio da igualdade pode ser visto de dois ângulos: a igualdade na lei, que tem a ver com a tarefa jurídico-política do legislador na elaboração da norma, e a igualdade perante a lei, que constitui imperativo a ser observado pelo aplicador do direito. Em outras palavras, tanto na elaboração como na aplicação da lei, há de ser observado o princípio da isonomia do tratamento.

Faz-se basilar esclarecer que a doutrina trata do princípio da igualdade juntamente com o princípio da não-discriminação, tendo em vista o natural liame que possuem.

O princípio da igualdade nada mais faz do que ventilar situaçóes, de forma que as pessoas compreendidas nestas venham a ser tratadas por critérios diferentes e que, para alguns, sejam deferidos determinados direitos e obrigaçóes que não assistem a outros, sendo que, os pontos de diferença que se atribuem para discriminar determinadas situaçóes devem ser decorrentes de aptidóes pessoais e não de outros critérios individuais personalíssimos (CISZEWSKI, 2005).

Nesse sentido, reitera-se a posição de que o teletrabalho, em hipótese alguma, deverá ser mecanismo de um possível isolamento do laborista. É necessário pôr a temática sob a lente de uma pesquisa com o norte de identificar não somente o isolacionismo imposto - mas, mormente, aquele que segrega o empregado do convívio social no ambiente laboral, deixando-lhe apenas os meios de comunição advindos das recentes inovaçóes tecnológicas.

Ademais, mesmo o uso dos meios de comunicação e informação deve partir da ideia de rede social, propulsora do convívio humano sadio e comprometido, virtual mas real.

\section{Referências}

ANDRADE, Pollyanna Vasconcelos Correia Lima de. Teletrabalho no ordenamento jurídico brasileiro. Revista do Tribunal Regional do Trabalho (13. Região), João Pessoa, v. 15, n. 1, p. 284-303, 2007. 
ARRUDA, Kátia Magalhães. Direito constitucional do trabalho: sua eficácia e o impacto do modelo neoliberal. São Paulo: LTr, 1998.

BAGGIO, A.M. A redescoberta da Fraternidade na época do "terceiro 1789". In: BAGGIO, A.M. (org) O principio esquecido 1: a fraternidade na reflexáo atual das ciências políticas. São Paulo: Cidade Nova, 2008.

BAGGIO, A.M. O principio esquecido 2. Exigências, recursos e definiçóes da fraternidade na política. São Paulo: Cidade Nova, 2009.

BARROS, Alice Monteiro de. Curso de direito do trabalho. 2. ed. São Paulo: LTr, 2006.

BARROS, Alice Monteiro de. Curso de direito do trabalho. 4. ed. rev. e ampl. São Paulo: LTr, 2008.

BELMONTE, Alexandre Agra. Problemas jurídicos do teletrabalho. Revista do Direito do Trabalho: São Paulo. n. 127, jul./set., 2007.

CASTELLS, M. O Poder da Identidade. São Paulo: Paz e Terra, 1999.

CASTELLS, M. Sociedade em Rede. São Paulo: Paz e Terra, 1999.

CISZEWSKI, Ana Claudia Vieira de Oliveira. O trabalho da pessoa portadora de deficiência. São Paulo: LTr, 2005.

DELGADO, Maurício Godinho. Curso de direito do trabalho. 4.ed. São Paulo: LTr, 2005.

DELGADO, Maurício Godinho. Curso de direito do trabalho. 5. ed. São Paulo: LTr. 2006.

DELGADO, Maurício Godinho. Proteçóes contra discriminação na relação de emprego. In: VIANA, Márcio Túlio; RENAULT, Luiz Otávio Linhares (Coord.). Discriminação. São Paulo: LTr, 2000.

DEON, Rodrigo. Os impactos sociais diante do ressurgimento das idéias liberais, e a dignidade da pessoa humana, como limite à flexibilização do Direito do Trabalho. DireitoNet, São Paulo, 04 fev. 2004. Disponível em: <http://www.direitonet.com. br/artigos/x/14/52/1452/>. Acesso em: 18 abr. 2011.

FINCATO, Denise Pires. Acidente do trabalho e teletrabalho: novos desafios à dignidade do trabalhador. Direitos Fundamentais e Justiça: Revista do Programa de PósGraduaçáo Mestrado e Doutorado em Direito da PUCRS. Porto Alegre: HS, v.2, n.4, jul./set. 2008.

FINCATO, Denise Pires. Teletrabalho: uma análise juslaboral. Revista Justiça do Trabalho, n. 236, ago. 2003.

FONSECA, M.A. Direito ao Trabalho: um direito fundamental no ordenamento jurídico brasileiro. São Paulo: LTr, 2009. 
FRANCO FILHO, Georgenor de Sousa. Globalizaçáo e desemprego: mudanças nas relaçóes de trabalho. São Paulo: LTr, 1998.

FRANCO FILHO, Georgenor de Souza. Reflexões sobre a desregulamentação do direito do trabalho: necessidade de preservar as garantias mínimas. Revista Trabalho e Processo, São Paulo, 7 (p. 20-8), dez.1995.

FRANCO FILHO, Georgenor de Sousa. Globalização e desemprego: mudanças nas relaçôes de trabalho. São Paulo: LTr, 1998.

HERNANDEZ, Márcia Regina Pozelli. Novas Perspectivas das Relaçóes de Trabalho: o teletrabalho. São Paulo: Ltr, 2011.

HOUAISS, A. e VILLAR, M.de S. Minidicionário da Língua Portuguesa. 3 ed. Rio de Janeiro: Objetiva, 2009.

JARDIM, Carla Carrara da Silva. O teletrabalho e suas atuais Modalidades. São Paulo: LTr, 2003.

LENUZZA, Letícia Maria Emanuelli. Teletrabalho: a tecnologia gerando uma nova forma de trabalho. 2007. 93 f. Dissertação (Mestrado - Concentração: Relaçôes de trabalho) - Programa de Pós-graduação em Direito, Universidade Federal de Caxias do Sul, Caxias do Sul, 2007.

LIMA, F.M.M. Os princípios do direito do trabalho na lei e na jurisprudência. São Paulo: LTr, 1994.

MACHADO, C.A.A. A fraternidade como categoria jurídico-constitucional. Disponível em http://www.portalciclo.com.br. Acessado em 18/04/2011.

MARQUES, Rafael da Silva. O Valor Social do Trabalho na Ordem Econômica, na Constituiçáo Brasileira de 1988. São Paulo: LTr, 2007.

MARQUES, Rafael da Silva. O valor social do trabalho na ordem econômica. In Cadernos da ANAMATRA IV, Porto Alegre, no 3, abr. /jun. 2007.

MARTINS, Sérgio Pinto. A continuidade do contrato de trabalho. São Paulo: Atlas, 2000.

MARTINS, Sérgio Pinto. Comentários à CLT. 12. ed. São Paulo: Atlas, 2008.

MARTINS, Sérgio Pinto. O direito do trabalho. 23. ed. São Paulo: Atlas, 2007.

MARTINS, Sérgio Pinto. Teletrabalho. Repertório IOB de Jurisprudência: Trabalhista e Previdenciário. São Paulo. v. 2, n. 18, 2001. p. 354.

MARX, Karl. Manuscritos econômicos e filosóficos e outros textos escolhidos. São Paulo: Abril Cultural, 1978.

WINTER, Vera Regina Loureiro. Teletrabalho: uma forma alternativa de emprego. São Paulo: LTr, 2005. 
MASI, Domenico de. O Futuro do Trabalho: fadiga e ócio na sociedade pós-industrial. Tradução de Yadyr A. Figueiredo. 5 ed. Rio de Janeiro: José Olympio, 2000.

MORAES, Renata Luciana. Teletrabalho muda relaçóes empregatícias. Disponível em: <http://www.conjur.com.br/2009-mai-25/teletrabalho-mudar-relacoes-entre-empregador-empregado>. Acesso em: 08 set. 2009.

NILLES, Jack M. Fazendo do teletrabalho uma realidade: um guia para telegerentes e teletrabalhadores. São Paulo: Futura, 1997.

OLIVEIRA, Cristiano de. O contrato do teletrabalhador. Justiça do Trabalho, v. 25, n. 289, p. 23-29, jan. 2008.

PADILLA, Antonio. Teletrabajo, Dirección y organización. Madrid: Rama, 1998.

PINTO, José Augusto Rodrigues; PAMPLONA FILHO, Rodolfo. Repertório de conceitos trabalhistas: direito individual. São Paulo: LTr, 2000. v. 1.

RENAULT, Luiz Otávio Linhares. Que é isto - o Direito do Trabalho. In: PIMENTA, José Roberto Freire Pimenta \& outros (coord.). Direito do Trabalho: Evoluçáo, crise e perspectivas. São Paulo: LTr, 2004.

SARLET, I.W. A Eficácia dos Direitos Fundamentais. Porto Alegre: do Advogado, 2004.

SARMENTO, D. Direitos Fundamentais e Relaçóes Privadas. Rio de Janeiro: Lúmen Júris, 2006.

SILVA, Luiz de Pinho Pedreira da. O teletrabalho. Revista LTr: Legislaçáo do Trabalho. São Paulo. v. 64, n. 5, maio, 2000.

SOARES JÚNIOR, Abeilar dos Santos. Configurações jurídicas do tele-emprego. Jus Navigandi, Teresina, ano 8, n. 475, 25 out. 2004. Disponível em: <http://jus2.uol. com.br/doutrina/texto.asp?id=5836>. Acesso em: 15 set. 2009.

SOUZA, Marcelo Rodrigo Soares de. Habitaçáo e informatização: o Teletrabalho. Disponível em <http://www.buscalegis.ufsc.br/arquivos/teletrabalho2.lia.pdf>. Acesso em 15 de agosto de 2009.

VALENTIM, João Hilário. Teletrabalho e relaçóes de trabalho. Revista do Ministério Público do Trabalho : Brasília. v. 10, n. 19, Março, 2000.

ZAMAGNI, S. Fraternità, il principio dimenticato.In: Giornale Agorà. Intrevista a Marco Girardo. 3 out.2009, p.25. 